\title{
Non-lethal assessment of reproductive characteristics for management and conservation of sharks
}

\author{
Cynthia A. Awruch ${ }^{1,5, *}$, Stewart D. Frusher ${ }^{2}$, Ned W. Pankhurst ${ }^{3}$, John D. Stevens ${ }^{4}$ \\ ${ }^{1}$ School of Aquaculture, University of Tasmania, Launceston, Tasmania 7250, Australia \\ ${ }^{2}$ Marine Research Laboratories, Tasmanian Aquaculture and Fisheries Institute, University of Tasmania, Hobart, \\ Tasmania 7053, Australia \\ ${ }^{3}$ Griffith University, Science, Environment, Engineering and Technology Group, Gold Coast, Queensland 9726, Australia \\ ${ }^{4}$ CSIRO, Marine and Atmospheric Research, Castray Esplanade, Hobart, Tasmania 7001, Australia \\ ${ }^{5}$ Present address: Marine Research Laboratories, Tasmanian Aquaculture and Fisheries Institute, University of Tasmania,
} Hobart, Tasmania 7053, Australia

\begin{abstract}
Chondrichthyans are one of the most vulnerable groups of marine species, with increasing numbers being listed as endangered or threatened. Fundamental to the conservation and management of any animal is an understanding of their reproduction and particularly, the size at which individuals enter the reproductive population. Size at maturity in sharks is typically obtained by macroscopic examination of the gonads after sacrificing the fish. Using the draughtboard shark Cephaloscyllium laticeps as a case study, we found that equivalent information can be obtained nondestructively using steroid hormone levels measured from a blood sample. This technique allowed us to release the shark after only 1 to 2 min of handling. A combination of plasma steroid hormone concentrations and an external measurement (total length for females and clasper length for males) was used to determine that over $90 \%$ of female and $95 \%$ of male sharks were either juveniles or adults. The estimates of size at maturity from the hormone analysis were within $3 \%$ of equivalent values of dissected sharks. Once validated, hormone levels can also be used to determine seasonal reproductive patterns for the adult population. Our results demonstrated how measurement of plasma levels of steroid hormones can provide a non-destructive method for obtaining reproductive data necessary for managing vulnerable and endangered shark species. The development of a non-destructive sampling tool also allows for improved ethical investigation into this vulnerable group of marine fishes.
\end{abstract}

KEY WORDS: Steroid hormones - Reproduction - Oviparous · Size at maturity $\cdot$ Cephaloscyllium laticeps $\cdot$ Draughtboard shark

\section{INTRODUCTION}

The decline and collapse of global fish stocks due to overexploitation is increasing, with several species nearing extinction (Dulvy et al. 2003, Cortés 2004, Mullon et al. 2005). These declines have called for conservation strategies to be developed for marine resources, such as implementing fisheries management policies, establishing a global system of marine protected areas (MPAs) or declaring some species as threatened or endangered so that their capture is prohibited. Due to the susceptibility of sharks to overfishing, with shark populations being harvested by commercial, artisanal and recreational fisheries (Bonfil 1994, Walker 1998), sharks are the focus of considerable international concern (Musick 1999, Stevens et al. 2000, Baum et al. 2003).

Many sharks have slow growth, long life span, late sexual maturity, low fecundity, a long gestation period and low natural mortality (Cortés 2000, Stevens et al. 
2000). These life history strategies make this group very vulnerable to high levels of fishing pressure and have led to the implementation of conservation and management strategies to protect populations from decline (Simpfendorfer \& Donohue 1998, Stevens et al. 2000, Musick 2004). To manage shark species, it is necessary to understand their life history strategies, including their size at maturity and reproductive cycles, to ensure that any management strategies include consideration of the capacity for sharks to reproduce and contribute to future generations.

Clasper calcification is the most common external method used to assess sexual maturity in male chondrichthyans (Clark \& Von Schmidt 1965); however, several authors have found maturity assessments based on calcification alone to be imprecise (Pratt 1979, Pratt \& Tanaka 1994) and Conrath (2004) suggested that maturity should be determined by combining the calcification of claspers with examination of the seminal vesicles. In females, macroscopic examination of the ovaries from dissected fish is the only method currently available to assess sexual maturity. Since there are many circumstances where killing the fish is inappropriate, as is the case for endangered or protected species, species residing in MPAs, or bycatch species that would normally be returned to the water alive, the development of nondestructive techniques to assess reproduction in sharks would be beneficial.

Over the last decade there has been an increased understanding of the reproductive endocrinology of chondrichthyans (Koob et al. 1986, Koob \& Callard 1999, Gelsleichter 2004, Sulikowski et al. 2005). Only a few studies have compared the levels of plasma steroid hormones between juvenile and adult chondrichthyans, and all of these suggest that hormones could be used as an indicator of maturational status (Rasmussen \& Gruber 1990, 1993, Rasmussen \& Murru 1992, Gelsleichter et al. 2002). Moreover, Sulikowski (2006) stated that measurement of steroid hormones holds promise as a relatively non-invasive approach for assessing maturity. While size at maturity has been obtained by combining steroid hormonal data with morphological and histological information (Sulikowski et al. 2005, 2006), no studies have been published that demonstrate the use of steroid hormones to obtain size at maturity without ancillary information. The present study demonstrates how hormone levels can provide estimates of size at maturity without the need to sacrifice the fish, using the draughtboard shark Cephaloscyllium laticeps (Duméril, 1853). This shark, one of the most common catsharks in the coastal areas of southern Australia, is an oviparous species that belongs to the family Scyliorhinidae. Direct macroscopic measures of gonadal condition in sacrificed draughtboard sharks were correlated with plasma levels of the reproductive hormones testosterone (T), 17 $\beta$ estradiol $\left(\mathrm{E}_{2}\right)$ and progesterone $\left(\mathrm{P}_{4}\right) . \mathrm{T}, \mathrm{E}_{2}$ and $\mathrm{P}_{4}$ were chosen as likely indices of maturity based on the strong correlation between these hormones and reproductive activity in a number of chondrichthyan species (Manire et al. 1995, Koob \& Callard 1999, Tricas et al. 2000).

\section{MATERIALS AND METHODS}

Data collection. Draughtboard sharks obtained from commercial and research surveys were used to calculate size at maturity and to validate plasma steroid levels against macroscopic examination of the gonads. A total of 609 female and 462 male sharks were collected throughout Tasmanian coastal waters (39 to $40^{\circ} \mathrm{S}$ and 143 to $149^{\circ} \mathrm{E}$ ) as bycatch from trap, gill-net and hook fisheries between June 2002 and April 2004. After capture, sharks were euthanised by immersion in a benzocaine bath consisting of 0.51 of benzocaine solution ( $40 \mathrm{~g}$ benzocaine in $1 \mathrm{l}$ ethanol) in 81 of seawater. For both sexes, total length (TL, mm) and gonadal weight $(\mathrm{g})$ were recorded. Calcification of the claspers, determined by assessing the rigidity by hand, and length of the clasper ( $\mathrm{mm}$, from the distal end of the metapterigyum to the tip) were recorded in males. Oviducal gland width $(\mathrm{mm}$, at the widest part) and presence of egg cases were recorded from females. Hormone analysis was undertaken on a subset of 229 sharks that were also dissected. This subset was derived from the same regions and time periods as the larger dataset to minimise any regional or seasonal differences. Blood samples ( 3 ml) from 118 females and 111 males were collected by caudal venipuncture from sharks before they were euthanised using pre-heparinized syringes fitted with 22 gauge needles. After extraction, blood samples were placed on ice for 3 to $6 \mathrm{~h}$ and then centrifuged for $5 \mathrm{~min}$ at $1000 \times \mathrm{g}$. The plasma was collected and stored at $-15^{\circ} \mathrm{C}$ until thawed for analysis.

Steroid hormone measurement. Levels of $\mathrm{E}_{2}, \mathrm{P}_{4}$ and $\mathrm{T}$ for both females and males were measured by radioimmunoassay. Plasma samples $(200 \mu l)$ were extracted twice with ethyl acetate $(1 \mathrm{ml})$ and $100 \mu \mathrm{l}$ aliquots were transferred to assay tubes for evaporation prior to addition of an assay buffer. Assay reagents for $E_{2}$ and $T$ were used as described by Pankhurst \& Carragher (1992). Progesterone was measured using $\left[1,2,6,7-{ }^{3} \mathrm{H}\right]$ progesterone supplied by Amersham Biosciences UK. The antibody is a polyclonal full serum antibody raised in sheep and was donated by Dr. Ken McNatty, Wallaceville Animal Research Station, Upper Hutt, New Zealand. The 
assay protocol used was as described by Pankhurst \& Carragher (1992). Steroid assays were validated by assessment of the slope of serial dilutions of extracted plasma against assay standards. Extraction efficiency was determined from recovery of ${ }^{3} \mathrm{H}$-labelled steroid added to pooled aliquots of plasma. Extraction efficiencies were 86,74 and $86 \%$ for $\mathrm{T}, \mathrm{E}_{2}$ and $\mathrm{P}_{4}$, respectively. Each sample was analysed in duplicate and the assay values were corrected accordingly to account for the extraction efficiency. The detection limit for all assays was $0.15 \mathrm{ng} \mathrm{ml}^{-1}$ plasma. Interassay variability was determined by repeat measurement of a pooled internal standard and coefficients of variation were $13 \%(n=9), 11 \%(n=9)$ and $9 \%(n=7)$ for $T, E_{2}$ and $\mathrm{P}_{4}$, respectively.

Classification of sexual stages using gonadal condition. Based on follicle stage and oviducal gland condition females were classified into 3 different reproductive stages. Juveniles had an ovary that contained previtellogenic follicles and a translucent oviducal gland of less than $9 \mathrm{~mm}$ diameter. Subadults had an ovary containing early vitellogenic follicles and an oviducal gland that was pinkish in colour and between 9 and $33 \mathrm{~mm}$ in diameter. Adults had an ovary containing vitellogenic or mature follicles with a red oviducal gland larger than $32 \mathrm{~mm}$ diameter (Awruch 2007). In the draughtboard shark clasper calcification (determined by assessing the rigidity of the clasper by hand) was found to be an accurate measure of reproductive stages in males. Juveniles had uncalcified claspers, subadults had partially calcified claspers and adults had fully calcified claspers (Awruch 2007).

Size at maturity based on gonadal condition. To establish size at maturity, oviducal gland width (for females) and clasper length (CL) (for males) were compared with TL. These morphological characteristics were chosen, as they increased progressively with maturity and were independent of the stage of the reproductive cycle. In contrast, gonadal weight will vary within mature sharks depending on the cycling gametogenic stage of the ovary or testis.

To determine the size at which $50 \%$ of the sharks mature, sharks were grouped into $25 \mathrm{~mm}$ length classes ranging from 170 to $1020 \mathrm{~mm}$. For both sexes, all fish that were not fully adults (e.g. subadults) were classified as juveniles. A logistic regression was applied to each sex separately. The proportion $(P)$ of adult fish at each $25 \mathrm{~mm}$ length class was obtained using the following equation (Neter et al. 1990):

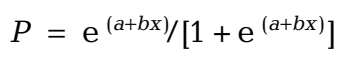

where $a$ and $b$ are constants and $x$ is the median value of the length class. Confidence intervals (CI) around the logistic model were obtained by conducting 1000 simulations in a bootstrapping routine where data were randomly sampled with replacement for each $25 \mathrm{~mm}$ length class (Turner et al. 2002). The middle $95 \%$ of the bootstrap replicates constituted the CIs. The parameters $P, a, b$ and $x$, and CIs were estimated using Excel (Microsoft ${ }^{\circledR}$ Excel 2000).

Classification of sexual stages using steroid hormone concentrations. For the 229 sharks that were dissected to obtain gonadal condition we also obtained blood samples for hormone analysis. To separate juveniles from adults using steroid hormone concentrations, we evaluated both linear discriminant function (LDF) analysis and multi-dimensional scaling (MDS) ordination.

Linear discriminant function: For females weighted averages of the predictive variables TL, T, $\mathrm{E}_{2}$ and $\mathrm{P}_{4}$ were used to obtain discriminant function scores $(D)$ to distinguish juveniles from adult sharks. Clasper calcification was strongly related to CL (Fig. 1). As clasper calcification was only recorded as uncalcified, partially calcified and calcified, we used CL as a continuous variable for the LDF. Weighted averages of $\mathrm{CL}, \mathrm{T}, \mathrm{E}_{2}$ and $\mathrm{P}_{4}$ were used to obtain the values of $D$ in males:

$$
D=B_{0}+B_{1} X_{1}+B_{2} X_{2}+\ldots+B_{i} X_{i}
$$

where $X_{i}$ is the value of each independent predictive variable (i) and $B_{i}$ is the coefficient estimated from the data. From the discriminant scores it was possible to obtain the probability that a shark was either a juvenile or adult as follows:

$$
P(G i / D)=\frac{P(D / G i) P(G i)}{\sum_{i=1}^{g} P(D / G i) P(G i)}
$$

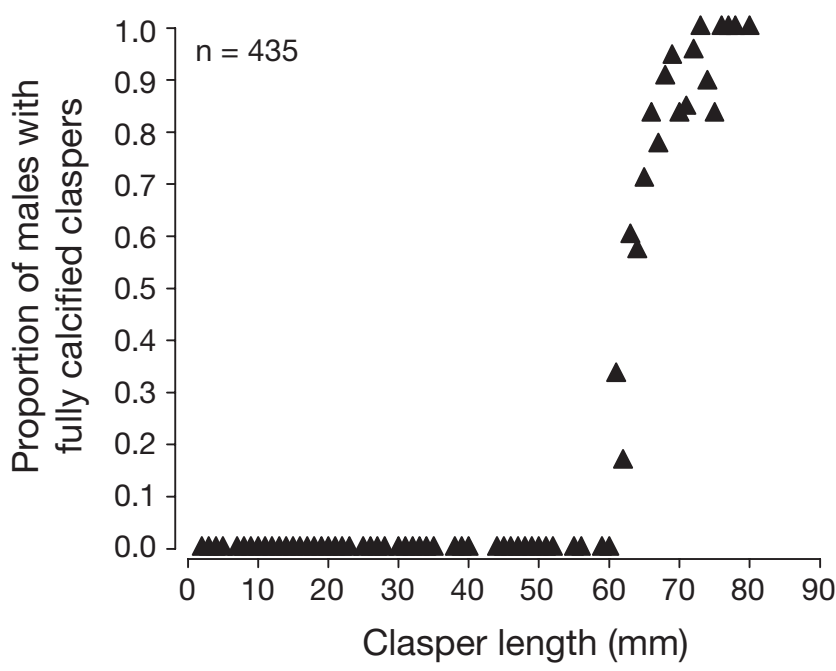

Fig. 1. Cephaloscyllium laticeps. Relationship between clasper calcification and clasper length 
where $P(G i)$ is the prior probability and is an estimate of the likelihood that a shark belongs to a specific group, $G$, where $i=$ juveniles or adults. The prior probability was calculated as the observed proportion of sharks in each group. The conditional probability $P(D / G i)$ is the probability of obtaining a particular value of $D$ if the shark belongs to a specific group. To calculate this probability, normal probability theory (the $D$ scores are normally distributed for each group) was assumed. Each shark was known to belong to a particular group, and the conditional probability of the observed $D$ score given membership in the group was calculated.

The predictive function was built using Excel and SPSS (SPSS ${ }^{\circledR}$ Base 10.0).

Multi-dimensional scaling: For both sexes, a MDS ordination based on the variables $\mathrm{T}$ and $\mathrm{E}_{2}$ (for females) and T and CL (for males) was used to separate juveniles and adults using normalized Euclidean distances. Data were transformed when necessary. To test the null hypothesis that there were no assemblage differences between groups (juveniles and adults) in the spatial matrix, a 1-way analysis of similarities (ANOSIM) and a pairwise test were performed. The MDS and ANOSIM were performed using the Primer ${ }^{\circledR} 5$ software package (Clarke \& Gorley 2001). Adults were separated using a $95 \%$ cut-off line. The line was calculated as the position on the MDS ordination where $95 \%$ of adults were correctly classified.

The significance level was set at $p=0.05$ for all data analyses.

Test case: sharks from a marine reserve. To demonstrate the use of the LDF and MDS methods we obtained blood samples from a new sample of 82 female and 54 male sharks captured in a marine reserve in southern Tasmania between May 2002 and May 2003 using rock lobster Jasus edwardsii traps. Blood samples were taken following the same procedure as described previously, and TL for each sex and CL for males were recorded prior to releasing the sharks. Based on the outcomes of the LDF and MDS analysis, size at maturity estimates were calculated for each method using Eq. (1).

\section{RESULTS}

\section{Size at maturity based on gonadal condition}

Oviducal gland width increased exponentially in female sharks between 750 and $850 \mathrm{~mm}$ TL (Fig. 2a). The largest juvenile female recorded was $850 \mathrm{~mm}$ TL and the smallest adult was $730 \mathrm{~mm}$ TL. For males, CL rapidly increased from approximately 650 to $780 \mathrm{~mm}$
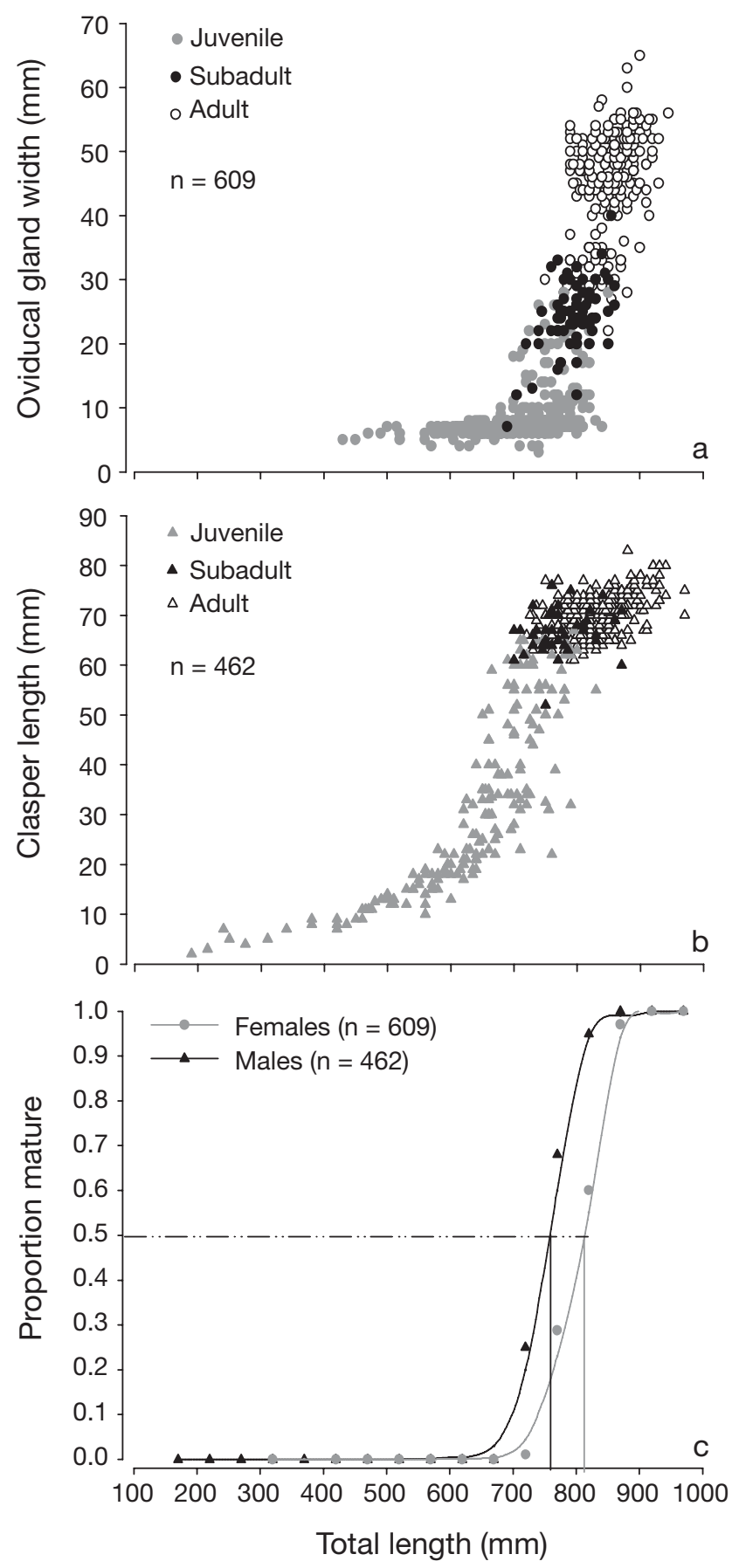

Fig. 2. Cephaloscyllium laticeps. Changes in (a) oviducal gland width (females) and (b) clasper length (males) with total length.

(c) Estimated maturity ogives for both sexes

TL (Fig 2b). The largest juvenile male recorded was $830 \mathrm{~mm}$ TL and the smallest adult male was $725 \mathrm{~mm}$ TL. Size at $50 \%$ maturity of females was estimated at $815 \mathrm{~mm}$ TL $\left(95 \% \mathrm{CI}=813\right.$ to $843 \mathrm{~mm}, \mathrm{r}^{2}=0.80, \mathrm{n}=$ 609), and $761 \mathrm{~mm} \mathrm{TL}\left(95 \% \mathrm{CI}=755\right.$ to $790 \mathrm{~mm}, \mathrm{r}^{2}=$ $0.84, \mathrm{n}=462$ ) for males (Fig. 2c). 


\section{Classification of the sexual stages using steroid hormone concentrations}

Linear discriminant function

Females: LDF analysis using TL, $\mathrm{T}, \mathrm{E}_{2}$ and $\mathrm{P}_{4}$ showed significant differences between juvenile and adult sharks (Wilk's lambda, $\chi^{2}=121.697, \mathrm{p}<0.001$ ). Both the standardized coefficient and the correlation of each variable with $D$ showed that TL was the main variable to contribute to the divergence between juveniles and adults. $T$ and $E_{2}$ contributed in similar proportion while $\mathrm{P}_{4}$ did not explain any additional separation between groups (Table 1). Therefore, the model was rerun excluding $\mathrm{P}_{4}$. D generated using TL, T and $\mathrm{E}_{2}$ were substituted into Eq. (2) as follows:

$$
D=-6.919+0.008 \times \mathrm{TL}+0.90 \times[\mathrm{T}]+0.22 \times\left[\mathrm{E}_{2}\right]
$$

Conditional probabilities under $D$ were generated for both groups. The prior probability of any shark to be juvenile was 0.63 and to be adult was 0.37 . From 118 females, $92 \%$ of cases were correctly classified.

Males: LDF analysis combining CL, $\mathrm{T}, \mathrm{E}_{2}$ and $\mathrm{P}_{4}$ showed significant differences between juveniles and adults (Wilk's lambda, $\chi^{2}=41.377, \mathrm{p}<0.001$ ). CL and T were the main contributors to the separation of juveniles and adults. Both $\mathrm{E}_{2}$ and $\mathrm{P}_{4}$ played a minor role in the divergence of the 2 groups and were excluded from the analysis (Table 1). D were generated using the following equation:

$$
D=-4.239+0.070 \times \mathrm{CL}+0.234 \times[\mathrm{T}]
$$

Conditional probabilities under $D$ were generated for juveniles and adults. The prior probability was estimated as 0.55 and 0.45 for juveniles and adults, respectively. From 111 males, 99\% of cases were correctly classified.

Table 1. Cephaloscyllium laticeps. Standardized discriminant function coefficients and correlations of the linear discriminant function (LDF) for females and males. Total length (TL, for females) and clasper length (CL, for males) showed the highest standardized coefficient and the highest relationship with the discriminant function. T: testosterone; $\mathrm{E}_{2}$ : $17 \beta$-estradiol $\mathrm{P}_{4}$ : progestrone

\begin{tabular}{|lccc|}
\hline Females & Variable & $\begin{array}{c}\text { Standardized } \\
\text { coefficient }\end{array}$ & $\begin{array}{c}\text { Correlation } \\
\text { with LDF }\end{array}$ \\
\hline \multirow{4}{*}{ Males } & $\mathrm{TL}$ & 0.61 & 0.90 \\
& $\mathrm{~T}$ & 0.42 & 0.80 \\
& $\mathrm{E}_{2}$ & 0.40 & 0.71 \\
& $\mathrm{P}_{4}$ & 0.16 & 0.58 \\
& $\mathrm{CL}$ & 0.89 & 0.96 \\
& $\mathrm{~T}$ & 0.59 & 0.78 \\
& $\mathrm{E}_{2}$ & 0.16 & 0.12 \\
& $\mathrm{P}_{4}$ & 0.07 & 0.27 \\
\hline
\end{tabular}

Multi-dimensional scaling (MDS)

Females: A combination of $\mathrm{T}$ and $\mathrm{E}_{2}$ separated the reproductive stages of female sharks. Based on the the LDF analysis, $\mathrm{P}_{4}$ was not included in the MDS analysis. The majority of adult sharks were on the left side of the ordination and the juveniles on the right side (stress $=0$ ); stress is used to calculate the goodness-of-fit of the analysis, and stress $<0.05$ is a good representation of the MDS (Fig. 3a). ANOSIM showed that there were significant differences between the reproductive stages (Global $\mathrm{R}=0.61$, $\mathrm{p}<0.001)$. A '95\% cut-off' line for adults resulted in $90 \%$ of the females being correctly classified; 8 juveniles were classified as adults and 5 adults as juveniles (Fig. 3a).
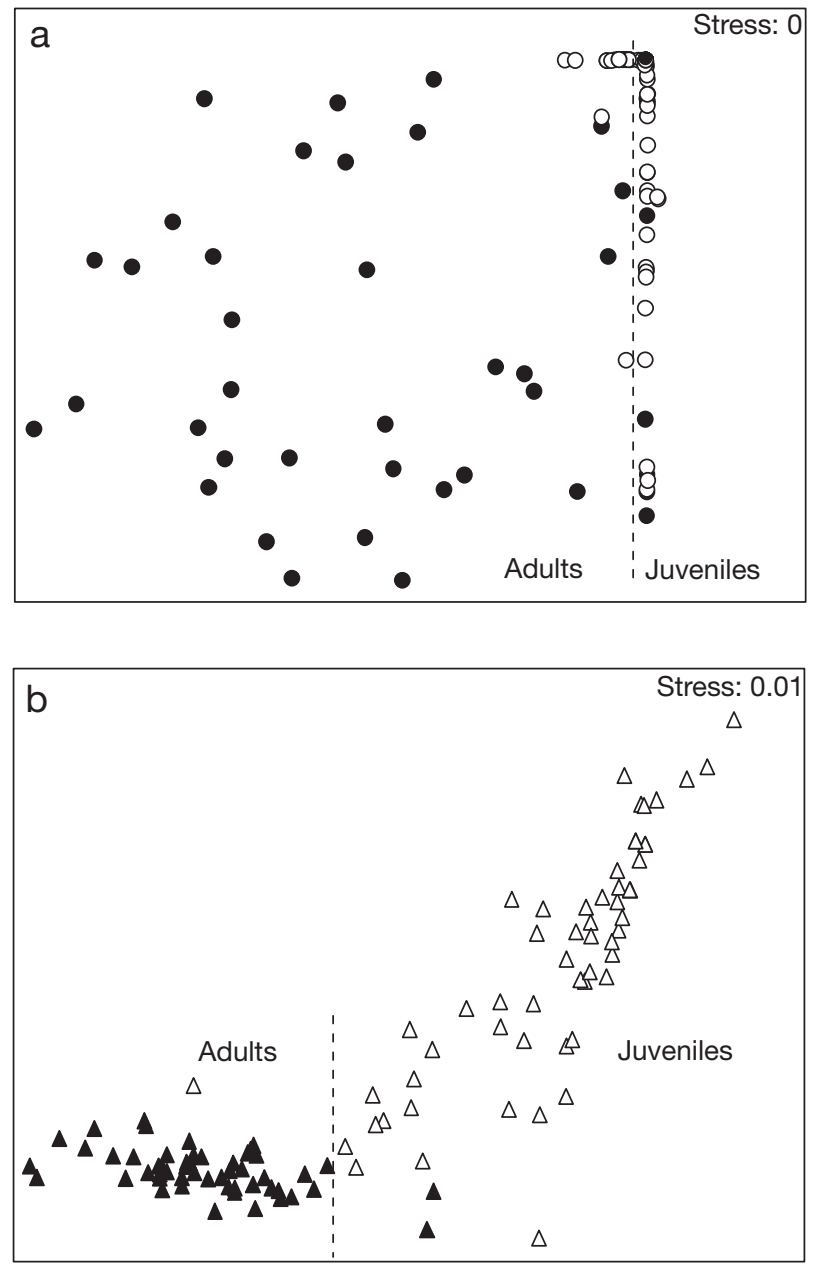

Fig. 3. Cephaloscyllium laticeps. (a) MDS ordination of juvenile $(O)$ and adult $(\bullet)$ females of known sexual stage, using testosterone $(\mathrm{T})$ and $17 \beta$-estradiol $\left(\mathrm{E}_{2}\right)$. (b) MDS of juvenile $(\Delta)$ and adult $(\boldsymbol{\Delta})$ males of known sexual stage, using clasper length and T. Vertical dashed lines represent the '95\% cut-off' line, with $95 \%$ of adults to the left of this line 
Males: Based on the results from the LDF analysis, $\mathrm{E}_{2}$ and $\mathrm{P}_{4}$ were excluded from the MDS analysis. A combination of CL and $\mathrm{T}$ separated adult male sharks from most of the juveniles (stress $=0.01$ ) and ANOSIM demonstrated that there were significant differences between the reproductive stages (Global $\mathrm{R}=0.70, \mathrm{p}<0.001$ ) (Fig. 3b). Based on a '95\% cut-off' line for adults, $97 \%$ of the 111 males sampled were correctly classified (Fig. 3b).

\section{Size at maturity based on steroid hormone concentrations}

Hormone analysis was undertaken on 229 sharks that were also dissected. Size at maturity was calculated for these sharks using Eq. (1) based on macroscopic examination of the gonads (destructive sampling) and after classification of the sharks into juveniles or adults using either LDF or MDS analysis (non-destructive sampling). Minor differences (i.e. $18 \mathrm{~mm}$ TL in males and $1 \mathrm{~mm}$ TL in females) were observed between the macroscopic derived estimates of the full dataset using 1071 sharks and the subset of 229 sharks. For the MDS method, sharks on the left of the '95\% cut-off' line were classified as adults and sharks on the right of the ' $95 \%$ cut-off' line were classified as juveniles. All 3 analyses resulted in a similar size at $50 \%$ maturity for both sexes, with females within $1.8 \%$ and males within $0.4 \%$ of the estimated values from macroscopic examination (Table 2). All males and females that were incorrectly classified in either analysis were within the $95 \%$ CI of the respective size at maturity estimate.

\section{Test case:}

sharks from a marine reserve

Draughtboard sharks from the marine reserve were categorized as juveniles or adults based on their posterior probabilities using Eqs. (4) \& (5) for females and males, respectively. For the MDS ordination, the unknown sharks were overlaid on the MDS plots obtained for sharks of known maturity (Fig. 4). Sharks that fell to the left of the '95\% cut-off' were classified as adults and those on the right as juveniles.

For both sexes, the LDF and MDS analyses resulted in a similar size at $50 \%$ maturity. Mean estimates of size at maturity for female and male draughtboard sharks caught in the marine reserve were within $3 \%$ of the values obtained from the rest of Tasmania (Table 2).
Table 2. Cephaloscyllium laticeps. Comparison of the size at 50\% maturity between destructive (macroscopic examination) and non-destructive (LDF and MDS) methods, and based on the hormone results of the LDF and MDS analyses. Percentage differences in the size at maturity using the non-destructive methods were compared with the macroscopic analysis. Negative percentages: size at maturity smaller than that obtained by macroscopic analysis

\begin{tabular}{|c|c|c|c|c|c|c|c|}
\hline & $\begin{array}{l}\text { Size at } \\
\text { maturity } \\
\mathrm{TL}(\mathrm{mm})\end{array}$ & $\begin{array}{c}\text { Difference } \\
(\%)\end{array}$ & $\mathrm{r}^{2}$ & a & $b$ & $\begin{array}{c}95 \% \mathrm{CI} \\
\mathrm{TL}(\mathrm{mm})\end{array}$ & $\mathrm{n}$ \\
\hline \multicolumn{8}{|c|}{ Destructive vs. non-destructive methods } \\
\hline \multicolumn{8}{|c|}{ Females } \\
\hline Macroscopic & 814 & & 0.80 & -32.16 & 0.04 & $798-830$ & 118 \\
\hline LDF & 823 & 1.10 & 0.77 & -59.55 & 0.07 & $812-832$ & 118 \\
\hline MDS & 829 & 1.84 & 0.75 & -28.54 & 0.03 & $811-848$ & 118 \\
\hline \multicolumn{8}{|l|}{ Males } \\
\hline Macroscopic & 779 & & 0.80 & -47.70 & 0.06 & $762-790$ & 111 \\
\hline LDF & 776 & -0.38 & 0.80 & -63.08 & 0.08 & $768-783$ & 111 \\
\hline MDS & 782 & 0.25 & 0.82 & -34.23 & 0.04 & $760-802$ & 111 \\
\hline \multicolumn{8}{|c|}{ Hormone results } \\
\hline \multicolumn{8}{|l|}{ Females } \\
\hline LDF & 818 & 0.49 & 0.77 & -72.09 & 0.09 & $803-855$ & 82 \\
\hline MDS & 828 & 1.71 & 0.75 & -9.44 & 0.01 & $775-870$ & 82 \\
\hline LDF & 768 & -1.41 & 0.80 & -43.84 & 0.06 & $745-803$ & 54 \\
\hline \multicolumn{8}{|l|}{ Males } \\
\hline MDS & 757 & -2.82 & 0.82 & -25.73 & 0.03 & $740-795$ & 54 \\
\hline
\end{tabular}

\section{DISCUSSION}

Size at maturity obtained from blood samples was within $3 \%$ of the size at maturity obtained from macroscopic examinations of gonads. For both sexes of draughtboard sharks, the combination of external features (e.g. TL in females and CL in males) and gonadal steroids can be used to obtain reproductive information for management of sharks without having to sacrifice the fish. From macroscopic examination of dissected sharks it was clear that maturity is strongly size dependent. Sharks larger than 860 and $870 \mathrm{~mm} \mathrm{TL}$ (females and males, respectively) were all adults and those below 750 and $710 \mathrm{~mm}$ TL (females and males, respectively) were all juveniles.

For draughtboard sharks, both LDF and MDS analyses provided objective methods to classify sharks as juveniles or adults, and therefore address size at maturity and reproductive seasonality. Within the intermediate length size class, sharks could be either juve- 

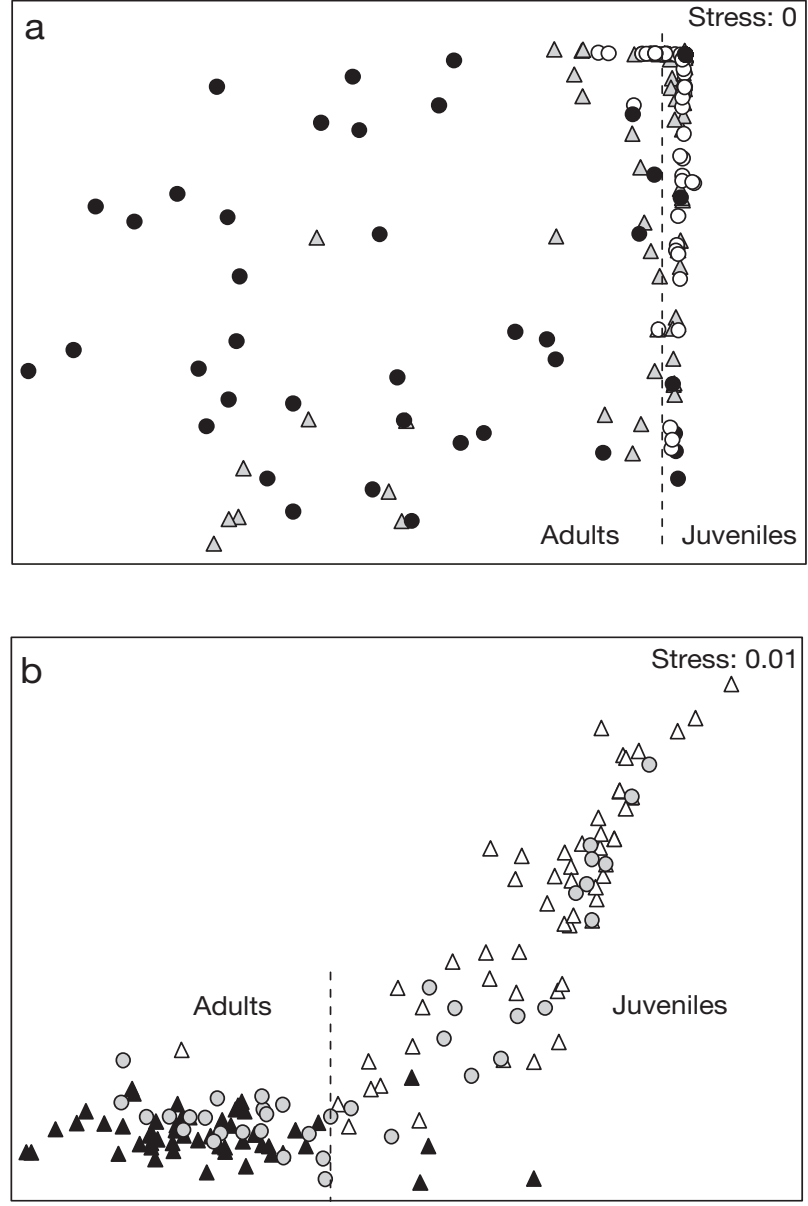

Fig. 4. Cephaloscyllium laticeps. (a) MDS ordination of females (known and unknown sexual stage) using $\mathrm{T}$ and $\mathrm{E}_{2}$. $\mathrm{O}=$ juveniles, $\boldsymbol{O}=$ adults, $\boldsymbol{\Delta}=$ unknown. (b) MDS ordination of males (known and unknown sexual stage) using clasper length and T. $\Delta=$ juveniles, $\boldsymbol{\Delta}=$ adults, $\bigcirc=$ unknown. Vertical dashed lines represent the '95\% cut-off' line, with 95\% of adults to the left of this line

niles or adults. While a small number of sharks were incorrectly classified, steroid hormones were able to determine the size at maturity for the majority of sharks in the intermediate length size class. For these sharks, neither TL or clasper calcification could be used to determine the reproductive maturity; however, plasma hormone levels did provide a mechanism for determining their reproductive status. The LDF had narrower confidence limits and was, in general, closer to the macroscopic estimates, giving a more precise and accurate method than the MDS. There were, however, no significant differences between sizes at maturity calculated by either method.

When selecting which hormones to use to separate juvenile or adult sharks, understanding the role that each of the gonadal steroids play in shark reproduction is important. For draughtboard sharks there was a need to measure only 2 hormones, $\mathrm{T}$ (for both sexes) and $E_{2}$ (for females), to separate juveniles from adults. Previous analysis showed that plasma levels of $\mathrm{T}$ and $\mathrm{E}_{2}$ were elevated during the follicular development phase of females, while elevated plasma $\mathrm{P}_{4}$ was found primarily in the ovulatory phase (Awruch 2007). As $P_{4}$ only varied in adult females and was dependent on the female ovulatory phase, it is possible to find adult females with low or high levels of $\mathrm{P}_{4}$, whereas juvenile females always have low levels of $\mathrm{P}_{4}$. Therefore, it was not surprising that $\mathrm{P}_{4}$ was not reliable as a discriminant factor for separating juvenile and adult females. In the case of males, only plasma $\mathrm{T}$ levels were found to increase with testes development (Awruch 2007). In draughtboard shark males, CL and $\mathrm{T}$ contributed to the separation of juveniles from adults. As the degree of calcification and size of claspers are external features that can be readily assessed, CL and clasper calcification will be the most cost effective method of identifying the size at sexual maturity of male sharks.

Steroid hormone levels may also be important in providing data on seasonality of reproduction. Although the draughtboard shark was not found to have a defined seasonal reproductive pattern, variations in hormone levels followed similar trends in reproductive activity obtained from macroscopic examination of the gonads (Awruch 2007). In seasonally reproducing species such as the epaulette shark Hemiscyllium ocellatum (Heupel et al. 1999), clearnose skate Raja eglanteria (Rasmussen et al. 1999) and Atlantic stingray Dasyatis sabina (Tricas et al. 2000), strong correlations between plasma steroid hormone levels and season have been reported. Thus, the application of this technique to seasonally reproducing species may also provide the ability to determine the timing of reproductive events such as follicle development, ovulation and gestation period.

A concern could be that the lower steroid plasma levels in seasonally reproductive sharks captured during their non-reproductively active period could confound the estimates of size at maturity as they would be classified as juveniles. Therefore, it is important to distinguish the period when sharks are reproductively active prior to determining the size at maturity using steroid plasma levels. Elevated steroid plasma levels would occur when adult sharks are reproductively active and all size classes should be selected from this period to determine size at maturity.

Our results clearly demonstrate that plasma levels of steroid hormones can be used to obtain reproductive characteristics for shark stocks equivalent to the conventional method of visual examination of 
gonads. Although we have only analysed 1 species of shark, the consistent relationship between maturity and plasma levels of $\mathrm{E}_{2}, \mathrm{~T}$ and $\mathrm{P}_{4}$ in other species (Tricas et al. 2000, Gelsleichter 2004, Sulikowski et al. 2006) suggest that these methods could be applied to all members of the group, and more broadly to the chondrichthyans due to their similarities in reproduction. While validation of the hormone levels for different members of the chondrichthyan group will require sacrificing a small number of individuals, the hormone levels may be sufficiently consistent among species or reproductive groups or, for the entire class, to minimise the need for validating each species.

Of particular importance for chondrichthyans is that the small blood sample required for hormone analysis can be obtained quickly with minimal handling time (2 to $3 \mathrm{~min}$ ) before the fish is returned to the water. The sample can be taken at sea in exposed conditions, making hormone measurement quick and minimally invasive. There are many situations where reproductive information is required for managing and monitoring chondrichthyan populations without a need to sacrifice the fish. These include bycatch species, species in marine reserves and threatened and endangered species. Reproductive hormones offer an ethical technique for sampling these sharks with minimal interference. Due to the increasing vulnerability of chondrichthyans, obtaining reproductive information without the need to sacrifice and dissect the fish is a significant contribution to their management and conservation.

Acknowledgements. We thank N. Moltschaniwskyj, A. Hirst and H. Pederson for help with the statistical analyses.

\section{LITERATURE CITED}

Awruch CA (2007) Reproduction and movement patterns of the draughtboard shark (Cephalloscylium laticeps), implications for bycatch management. PhD thesis, University of Tasmania

Baum JK, Myers RA, Kehler DG, Worm B, Harley SJ, Doherty PA (2003) Collapse and conservation of shark populations in the Northwest Atlantic. Science 299:389-392

Bonfil R (1994) Overview of world elasmobranch fisheries, Vol 341. FAO, Rome

Clark E, Von Schmidt K (1965) Sharks of the central gulf coast of Florida. Bull Mar Sci 15:13-83

Clarke KR, Gorley RN (2001) Primer v5: user manual/tutorial. Plymouth

Conrath C (2004) Reproductive biology. In: Musick JA, Bonfil $\mathrm{R}$ (eds) Elasmobranch fisheries management techniques. APEC, Singapore, p 133-164

Cortés E (2000) Life history patterns and correlations in sharks. Rev Fish Sci 8:299-344

Cortés E (2004) Life history patterns, demography, and popu- lation dynamics. In: Carrier JC, Musick JA, Heithaus MR (eds) Biology of the sharks and their relatives. CRC Press, London, p 449-469

Dulvy NK, Sadovy Y, Reynolds JD (2003) Extinction vulnerability in marine populations. Fish Fish 4:25-64

Gelsleichter J (2004) Hormonal regulation of elasmobranch physiology. In: Carrier JC, Musick JA, Heithaus MR (eds) Biology of sharks and their relatives. CRC Press, London, p 287-323

Gelsleichter J, Rasmussen LEL, Manire CA, Tyminski B, Chang B, Lombardi-Carlson L (2002) Serum steroid concentrations and development of reproductive organs during puberty in male bonnethead sharks, Sphyrna tiburo. Fish Physiol Biochem 26:398-401

Heupel MR, Whittier JM, Bennett MB (1999) Plasma steroid hormone profiles and reproductive biology of the Epaulette shark, Hemiscyllium ocellatum. J Exp Zool 284:586-594

Koob TJ, Callard IP (1999) Reproductive endocrinology of female elasmobranchs: lessons from the little skate (Raja erinacea) and spiny dogfish (Squalus acanthias). J Exp Zool 284:557-574

Koob TJ, Tsang P, Callard IP (1986) Plasma estradiol, testosterone, and progesterone levels during the ovulatory cycle of the skate (Raja erinacea). Biol Reprod 35:267-275

Manire CA, Rasmussen LEL, Hess DL, Hueter RE (1995) Serum steroid hormones and the reproductive cycle of the female bonnethead shark, Sphyrna tiburo. Gen Comp Endocrinol 97:366-376

Mullon C, Fréon P, Cury P (2005) The dynamics of collapse in world fisheries. Fish Fish 6:111-120

Musick JA (1999) Ecology and conservation of long-lived marine animals. In: Musick JA (ed) Life in the slow lane: ecology and conservation of long-lived marine animals. Am Fish Soc Symp 23:1-10

Musick JA (2004) Management of sharks and their relatives (Elasmobranchii). In: Musick JA, Bonfil R (eds) Elasmobranch fisheries management techniques. APEC, Singapore, $\mathrm{p}$ 1-6

Neter J, Kutner MH, Nachtsheim CJ, Wassermann W (1990) Applied linear statistical models, 4th edn. Irwin, Chicago, IL

Pankhurst NW, Carragher JF (1992) Oocyte maturation and changes in plasma steroid levels in snapper Pagrus (=Chrysophrys) auratus (Sparidae) following treatment with human chorionic gonadotropin. Aquaculture 101:337-347

Pratt HL (1979) Reproduction in the blue shark Prionace glauca. Fish Bull 77:445-470

Pratt HL, Tanaka S (1994) Sperm storage in male elasmobranchs: a description and survey. J Morphol 219:297-308

Rasmussen LEL, Gruber SH (1990) Serum levels of circulating steroid hormones in free-ranging carcharhinoid sharks. In: Pratt HL, Gruber SH, Taniuchi T (eds) Elasmobranchs as living resources: advances in the biology, ecology, systematics, and the status of the fisheries. NOAA NMFS Tech Rep 90, Washington, p 143-155

Rasmussen LEL, Gruber SH (1993) Serum concentrations of reproductively-related circulating steroid hormones in the free-ranging lemon shark, Negaprion brevirostris. Environ Biol Fishes 38:167-174

Rasmussen LEL, Murru FL (1992) Long-term studies of serum concentrations of reproductively related steroid hormones in individual captive carcharhinids. Aust J Mar Freshw Res 43:273-281

Rasmussen LEL, Hess DL, Luer CA (1999) Alterations in serum steroid concentrations in the clearnose skate, Raja eglanteria: correlations with season and reproductive status. J Exp Zool 284:575-585 
Simpfendorfer CA, Donohue K (1998) Keeping the fish in 'fish and chips': research and management of the Western Australia shark fishery. Mar Freshw Res 49:593-600

Stevens JD, Bonfil R, Dulvy NK, Walker PA (2000) The effects of fishing on sharks, rays, and chimaeras (chondrichthyans), and the implications for marine ecosystems. J Mar Sci 57:476-494

Sulikowski JA, Tsang PCW, Huntting Howell W (2005) Age and size at sexual maturity for the winter skate, Leucoraja ocellata, in the western Gulf of Maine based on morphological, histological and steroid hormone analysis. Environ Biol Fishes 72:429-441

Sulikowski JA, Kneebone J, Elzey S, Jurek J, Howell WH, Tsang PCW (2006) Using the composite variables of repro-

Editorial responsibility: John Choat,

Townsville, Queensland, Australia ductive morphology, histology and steroid hormones to determine age and size at sexual maturity for the thorny skate Amblyraja radiata in the western Gulf of Maine. J Fish Biol 69:1449-1465

Tricas TC, Maruska KP, Rasmussen LEL (2000) Annual cycles of steroid hormone production, gonad development, and reproductive behavior in the Atlantic stingray. Gen Comp Endocrinol 118:209-225

Turner K, Gardner C, Swain R (2002) Onset of maturity in male southern rock lobsters Jasus edwardsii in Tasmania, Australia. Invertebr Reprod Dev 42:129-135

Walker TI (1998) Can shark resources be harvested sustainably? A question revisited with a review of shark fisheries. Mar Freshw Res 49:533-572

Submitted: May 29, 2007; Accepted: August 28, 2007

Proofs received from author(s): February 6, 2008 